'Fundação Oswaldo Cruz (Fiocruz), Centro de Estudos e Pesquisas em Emergências e Desastres em Saúde (Cepedes) - Rio de Janeiro (RJ), Brasil. marianoandradesilva@ gmail.com

2 Fundação Oswaldo Cruz (Fiocruz), Instituto de Comunicação e Informação Científica e Tecnológica em Saúde (Icict) - Rio de Janeiro (RJ), Brasil.

3 Universidade Federal do Rio de Janeiro (UFRJ), Laboratório de GeoHidroecologia e Gestão de Riscos (Geoheco) - Rio de Janeiro (RJ), Brasil.

\section{Do global ao local: desafios para redução de riscos à saúde relacionados com mudanças climáticas, desastre e Emergências em Saúde Pública}

\author{
From global to local: challenges to reduce health risks related to \\ climate change, disasters, and Public Health Emergencies
}

Mariano Andrade da Silva', Diego Ricardo Xavier², Vânia Rocha'1,3

DOI: 10.1590/0103-11042020E204

RESUMO Pela primeira vez na história, presenciam-se transformações no padrão esperado do clima com consequências ainda desconhecidas para sociedade industrial moderna. Esses riscos globais ocorrem em um mundo cada vez mais conectado, com população crescente e ambientalmente degradado, tendo como pano de fundo um cenário em que há uma relação proporcionalmente inversa entre os países, populações e grupos sociais que sofrem, de modo mais amplo e intenso, os riscos e danos provocados pelas mudanças climáticas. Um dos impactos imediatos já observados é o aumento na frequência e na magnitude de eventos extremos, gerando cenários propícios ao surgimento de emergências em saúde. Este artigo teve como objetivo apresentar os principais desafios para redução de riscos à saúde relacionados com mudanças no clima, desastre e Emergências em Saúde Pública; os principais avanços nas políticas sobre o tema; e ações de saúde dentro desse complexo cenário social, ambiental e sanitário iminente. Como resultado, apresentam-se os principais acordos globais relacionados e as necessidades de ampliação do Sistema Nacional de Redução de Riscos à Saúde visando fortalecer as ações necessárias, a fim de obter resposta adequada aos fatores de risco apresentados. Para tanto, apresentam-se seis recomendações necessária à elaboração desse sistema.

PALAVRAS-CHAVE Risco à saúde humana. Mudança climática. Emergências. Capacidade de resposta ante emergências.

\begin{abstract}
For the first time in history, transformations in the expected pattern of the climate are witnessed with consequences still unknown for modern industrial society. These global risks occur in an increasingly connected world, with a growing and environmentally degraded population, against the background of a scenario in which there is a proportionately inverse relationship between countries, populations and social groups that suffer, in a broader and more intense way, the risks and damages caused by climate change. One of the immediate impacts already observed is the increase in the frequency and magnitude of extreme events, generating scenarios favorable to the emergence of health emergencies. This article aimed to present the main challenges for reducing health risks related to climate change, disaster and Public Health Emergencies; the main advances in policies on the subject; and health actions within this complex imminent social, environmental and health scenario. As a result, the main related global agreements and the needs to expand the National Health Risk Reduction System are presented, aiming at strengthening the necessary actions, in order to obtain an adequate response to the risk factors presented. To this end, six recommendations are presented that are necessary for the elaboration of this system.
\end{abstract}

KEYWORDS Health risk. Climate change. Emergencies. Surge Capacity. 


\section{Introdução}

Mudanças climáticas, ameaças terroristas, acidentes com agentes Químicos, Biológicos e Radionucleares (QBRN), insegurança alimentar, hesitação vacinal, resistência microbiana, associadas às iniquidades em saúde, geram os fatores de risco que compõem um cenário complexo e propício ao surgimento de Emergências em Saúde Pública (ESP). Os impactos sobre o sistema social, em decorrência disso, podem ser diretos e indiretos, variando em escalas locais e globais.

A emissão de gases de efeito estufa e as mudanças climáticas têm provocado aumento na frequência e intensidade dos fenômenos climáticos; e, em alguns casos, tornando-se a gênese de ESP. Não se trata mais apenas dos impactos que os desastres relacionados com o clima provocam no nível local, mas de processos globais que envolvem riscos de difícil compreensão e gestão ${ }^{1}$.

Concomitantemente, a conexão entre pessoas, lugares e mercadorias no mundo contemporâneo torna cada vez mais rápida a disseminação de agentes patogênicos. Atentados, sobretudo com agente químicos e biológicos, provocados com objetivos de afirmação política por parte de grupos extremistas, têm sido uma preocupação constante entre líderes governamentais, principalmente durante eventos de massa, como Olimpíadas e Copa do Mundo. Somam-se a isso as instabilidades políticas em um cenário econômico neoliberal, que potencializa situações de crise e conflitos ao mesmo tempo que reduz a capacidade de resposta local, intensificando a coexistência de velhos e novos problemas de saúde.

Nesse cenário, a produção industrial segmentada internacionalmente em suas diferentes etapas (extração, produção, transporte e armazenamento) tem resultado em eventos com grandes impactos locais e regionais sobre o meio ambiente, atingindo populações variando de dezenas a milhares de pessoas, como nos desastres de origem química como Seveso em 1976 e Bhopal em 1984, ou nuclear, como
Three Mile Island em 1979, Chernobyl em 1986 e Fukushima em 2011², Samarco em Mariana (MG) em 2015 e Vale S.A. em Brumadinho (MG) em $2019^{3}$.

Os desafios que se colocam nos níveis globais e locais incluem a sobreposição de eventos e potencializam riscos existentes. Desastres naturais podem ser combinados com desastres tecnológicos, que são muitas vezes seguidos de crises humanitárias ou conflitos, que podem ainda desencadear eventos epidêmicos e ESP. Essas situações, na maioria das vezes, são moduladas pelas precárias condições de vida em que se encontra grande parcela populacional ${ }^{4,5}$.

Tais conjunturas reativam antigos e trazem novos desafios para a saúde coletiva, pois, além dos cenários de risco conhecidos, intensificados por conta de vulnerabilidades socioambientais, é necessário planejamento para tomada de decisão em cenários prospectivos (e incertos), envolvendo sobreposição de riscos. Nesse contexto, este artigo tem como objetivo apresentar os principais desafios para redução de riscos à saúde relacionados com mudanças no clima, desastre e ESP; os avanços nas políticas internacionais sobre o tema; e recomendações para fortalecer as ações de saúde pública dentro desse complexo cenário social, ambiental e sanitário iminente.

\section{Do desenvolvimento econômico às mudanças climáticas: principais desafios da modernidade}

As ações humanas são responsáveis pelo processo de aquecimento global, uma das múltiplas consequências da mudança do padrão climático. O desenvolvimento da sociedade contemporânea acelerou o processo de emissão de dióxido de carbono (CO2) e de outros gases de efeito estufa, como o metano (CH4) e o óxido nitroso (N2O). Os efeitos desses gases combinados ao processo de ocupação e manejo da terra são considerados os 
responsáveis pelo processo de aquecimento global. Essas conclusões foram apontadas nos relatórios do Painel Intergovernamental sobre Mudanças Climáticas (IPCC) nos anos de 2007 e 2014. Considerando a produção desses gases em nível mundial, o CO2 é responsável pela maior parte do efeito nesse sistema. No Brasil, evidencia-se que a produção de gás $\mathrm{CH} 4$ é responsável pela maior parcela de produção de gases de efeito estufa, boa parte dessa produção relacionada com atividades de desmatamento e com o agronegócio ${ }^{6}$.

Um aspecto importante a ser destacado nesse processo é que, pela primeira vez na história, estamos diante de transformações no clima que são desconhecidas para as civilizações humanas passadas e para a sociedade industrial moderna ${ }^{7}$. Nesse sentido, uma das metas propostas pelos Objetivos de Desenvolvimento Sustentável (ODS) é entender a dinâmica de produção de gases de efeito estufa, propor ações de mitigação dos danos e diminuir o impacto presente e futuro das alterações climáticas.

Um dos impactos imediatos observados do sistema complexo das mudanças climáticas globais é o aumento na frequência e na magnitude de eventos extremos, a alterações no ciclo hidrológico (aumento de secas e inundações), a elevação dos níveis dos oceanos e o aumento da ocorrência de tempestades. Eventos extremos, quando combinados com outros fatores, como o processo de ocupação do espaço e condições de vulnerabilidade das populações, podem gerar desastres ${ }^{\mathbf{8}}$.

Os desastres apresentam características importantes, que podem ser combinadas ou não. A primeira delas é resultar em uma séria interrupção do funcionamento normal de uma comunidade, afetando seu cotidiano por meio de perdas materiais e econômicas, danos ambientais e à saúde das populações. A segunda é exceder a capacidade de uma comunidade ou sociedade afetada em lidar com a situação utilizando seus próprios recursos, o que pode resultar na ampliação das perdas e danos, bem como doenças e óbitos ${ }^{8}$.

Os riscos climáticos que vêm se intensificando não se limitam apenas aos efeitos dos desastres, mas produzem impactos sobre a saúde humana por diferentes vias e intensidades, especialmente aos mais vulneráveis - crianças, idosos e pessoas com problemas crônicos de saúde. Algumas dessas mudanças impactam de forma direta e imediata. No entanto, na maior parte das vezes, esse impacto é indireto, sendo mediado por mudanças no ambiente, como a alteração de ecossistemas, a perda de biodiversidade e a alteração dos ciclos biogeoquímicos, como demonstrado no quadro 1. 
Quadro 1. Efeitos sanitários previstos como consequências das variabilidades climáticas

\begin{tabular}{|c|c|c|c|c|}
\hline & $\begin{array}{l}\text { Efeitos das Mudanças } \\
\text { climáticas }\end{array}$ & Risco Sanitário & Efeitos sanitários & $\begin{array}{l}\text { Índice de confiança } \\
\text { (Fator de certeza de sua } \\
\text { ocorrência) }\end{array}$ \\
\hline \multirow[t]{2}{*}{ 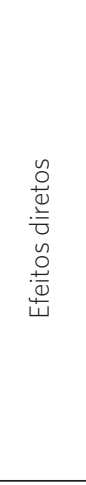 } & $\begin{array}{l}\text { Aumento no número de dias } \\
\text { e noites quentes; aumento na } \\
\text { frequência e intensidade das } \\
\text { ondas de calor; aumento do } \\
\text { risco de incêndios em condi- } \\
\text { ções de baixa pluviosidade }\end{array}$ & $\begin{array}{l}\text { Mortalidade excessiva relacionada ao } \\
\text { calor; maior incidência de insolação, es- } \\
\text { pecialmente entre trabalhadores, atletas } \\
\text { e idosos; agravamento das doenças cir- } \\
\text { culatórias, cardiovasculares, respiratórias } \\
\text { e nefropáticas; aumento da mortalidade } \\
\text { prematura relacionada ao ozônio e polui- } \\
\text { ção do ar por incêndios, especialmente } \\
\text { durante ondas de calor }\end{array}$ & $\begin{array}{l}\text { Aumento do risco de lesões, } \\
\text { doenças e mortes devido a } \\
\text { ondas de calor e incêndios } \\
\text { mais intensos }\end{array}$ & Muito alto \\
\hline & $\begin{array}{l}\text { Diminuição do número de } \\
\text { dias e noites frias }\end{array}$ & $\begin{array}{l}\text { Em climas frios e temperados, menor mor- } \\
\text { talidade relacionada ao frio e diminuição de } \\
\text { doenças cardiovasculares e respiratórias, } \\
\text { particularmente entre os idosos }\end{array}$ & $\begin{array}{l}\text { Diminuição da mortalidade } \\
\text { e morbidade relacionadas } \\
\text { ao frio }\end{array}$ & Baixo \\
\hline \multirow{2}{*}{ 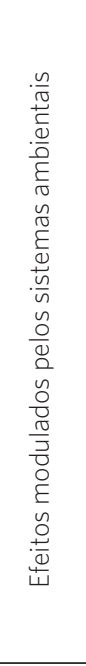 } & $\begin{array}{l}\text { Aumento de temperatura e } \\
\text { umidade; aumento na varia- } \\
\text { ção do comportamento das } \\
\text { chuvas; temperaturas mais } \\
\text { altas da superfície do mar } \\
\text { e rios }\end{array}$ & $\begin{array}{l}\text { Crescimento microbiano acelerado e maior } \\
\text { sobrevivência, persistência, transmissão e } \\
\text { virulência de patógenos; modificação da } \\
\text { distribuição geográfica e sazonal de doen- } \\
\text { ças e mudanças ecológicas (por exemplo, } \\
\text { proliferação de algas nocivas); escassez de } \\
\text { água; inundações que danificam a infraes- } \\
\text { trutura de abastecimento de água e sane- } \\
\text { amento; contaminação de fontes de água } \\
\text { por escoamento }\end{array}$ & $\begin{array}{l}\text { Aumento dos riscos de doen- } \\
\text { ças transmitidas por alimen- } \\
\text { tos e água }\end{array}$ & Muito alto \\
\hline & $\begin{array}{l}\text { Aumento de temperatura } \\
\text { e umidade; mudança na } \\
\text { intensidade e frequência dos } \\
\text { índices pluviométricos. }\end{array}$ & $\begin{array}{l}\text { Replicação parasitária acelerada e aumento } \\
\text { da frequência de acidentes com animais } \\
\text { peçonhentos; período de transmissão } \\
\text { epidemiológicos mais longas; reemergên- } \\
\text { cia de doenças anteriormente prevalentes; } \\
\text { mudança de distribuição e abundância de } \\
\text { vetores de doenças; menos eficácia das } \\
\text { intervenções de controle de vetores }\end{array}$ & $\begin{array}{l}\text { Riscos aumentados de doen- } \\
\text { ças transmitidas por vetores }\end{array}$ & Médio \\
\hline \multirow{2}{*}{ 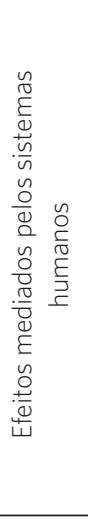 } & $\begin{array}{l}\text { Aumento de temperaturas e } \\
\text { mudanças na precipitação }\end{array}$ & $\begin{array}{l}\text { Redução da produção de alimentos; re- } \\
\text { dução do acesso aos alimentos devido } \\
\text { à contração da oferta e ao aumento dos } \\
\text { preços; efeitos combinados de desnutrição } \\
\text { e doenças infecciosas; efeitos crônicos } \\
\text { com consequências no desenvolvimento } \\
\text { metabólico/fisiológico podendo apresentar } \\
\text { nanismo e outras complicações crônicas. }\end{array}$ & $\begin{array}{l}\text { Aumento do risco de desnu- } \\
\text { trição devido à redução da } \\
\text { produção de alimentos em } \\
\text { regiões pobres }\end{array}$ & Alto \\
\hline & $\begin{array}{l}\text { Temperaturas e umidade } \\
\text { aumentadas }\end{array}$ & $\begin{array}{l}\text { Trabalhadores ao ar livre e desprotegidos, } \\
\text { forçados a trabalhar em condições insegu- } \\
\text { ras, ou perda de oportunidades de renda e } \\
\text { sustento }\end{array}$ & $\begin{array}{l}\text { Consequências sobre a saúde } \\
\text { dos trabalhadores, incluindo } \\
\text { a perda de capacidade de } \\
\text { trabalho e a redução da pro- } \\
\text { dutividade do trabalho em } \\
\text { populações vulneráveis }\end{array}$ & Alto \\
\hline 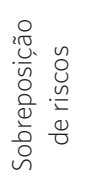 & Mudança climática geral & Combinação dos riscos indicados acima & $\begin{array}{l}\text { Efeitos negativos sobre a } \\
\text { saúde superariam os efeitos } \\
\text { positivos }\end{array}$ & Alto \\
\hline
\end{tabular}

Fonte: Adaptado de $\mathrm{WHO}^{7}$ 
Além dos desastres com origem em processos climáticos e meteorológicos, é importante destacar a categoria dos desastres tecnológicos que podem ter origem nas diferentes etapas do processo produtivo das sociedades industriais modernas, que envolve desde a extração de matérias primas e energia até o processamento e produção, transporte e armazenamento, bem como descarte final, envolvendo principalmente produtos químicos e radionucleares.

Hogan, citado por Bonatti e Carmo 9 , elenca alguns dos principais desastres tecnológicos que influenciaram uma nova percepção sobre a degradação ambiental no mundo. Além de impactos diretos, mensurados em danos físicos, econômicos e sociais, os danos em longo prazo são dificilmente estimados, dado que os riscos desses eventos podem se ampliar no tempo e no espaço. Entre os eventos, os autores citam a contaminação química por mercúrio em Minamata (Japão) em 1956 e do Love Canal em Nova Iorque na década de 1980, a nuvem tóxica em Seveso na Itália em 1976, o vazamento de gás em Bhopal na Índia em 1984, o desastre nuclear de Chernobyl em 1986.

No Brasil, destacam-se os recentes desastres envolvendo a mineração. O primeiro, envolvendo a mineradora Samarco (uma subsidiária da Vale S.A.), em 2015, com 19 óbitos, abrangendo 50 milhões de metros cúbicos de rejeitos e atingindo 36 municípios em uma extensão de 650 $\mathrm{km}$ ao longo da Bacia do rio Doce. O segundo, envolvendo a Vale S.A., em 2019, entre desaparecidos e óbitos, totaliza cerca de 270 vítimas, constituindo o maior acidente de trabalho já ocorrido no Brasil. Além de vítimas fatais e afetados, esse desastre envolveu 13 milhões de metros cúbicos de rejeitos, atingindo, ao menos, 18 municípios. Em ambos os desastres, os impactos socioambientais nas bacias dos rios Doces e Paraopeba foram intensos; liberado ao meio ambiente grande quantidade de rejeitos e elevados níveis de contaminação por metais pesados, modificando as condições de vida e trabalho de milhões de pessoas e ameaçando os serviços ecossistêmicos e os modos de sobrevivência das futuras gerações ${ }^{\mathbf{1 0}}$.
Em outras situações, os desastres naturais podem desencadear também desastres tecnológicos, como no caso de Fukushima, Japão, registrado em 11 de março de 2011, quando um terremoto atingiu a Ilha do Japão. Como consequência, um tsunami atingiu a usina nuclear de Fukushima ampliando os danos. O evento levou a óbito mais de 18.500 pessoas de forma direta, contudo, os efeitos na saúde da população por conta do vazamento nuclear geraram exposição de difícil contabilização, demandando monitoramento da área e acompanhamento dos atingidos no longo prazo"1.

Ambas as situações de desastres revelam a necessidade de trabalhar de modo integrado, pois tanto um desastre tecnológico pode acarretar um desastre relacionado com crises hídricas, como ocorrido em Brumadinho e a consequente contaminação do Rio Paraopeba, como um desastre de origem natural pode desencadear um desastre de origem tecnológica, como ocorrido em Fukushima.

Ademais, nesses processos, há tanto os que se relacionam com as mudanças e variabilidade climática como também os que envolvem as grandes transformações ecológicas provocadas pelos padrões de desenvolvimento econômico. Anyamba et al.12 demonstraram que o intenso El Niño de 2015-2016 resultou em condições de anomalia climática e ambiental. Em regiões específicas do mundo, essa condição favoreceu surtos e/ou amplificação de doenças como chikungunya, hantavírus, febre do vale do Rift, cólera, peste e zika. Sanders et al. ${ }^{5}$, ao abordar a emergência envolvendo Ebola, destacam os processos sociais e econômicos que estiveram na base do evento, envolvendo desde guerras civis até a rápida expansão do agronegócio e da indústria de extração de minérios, com abertura de novas estradas e desmatamento em larga escala para ampliar as novas áreas de exploração. Para esses autores, a combinação das alterações ecológicas modificou os circuitos de circulação dos patógenos e das populações; associada a existências de sistemas sociais desestruturados, estabeleceram as bases para ESP do Ebola nos países africanos. 
Entre os anos de 2016 e 2018, o Brasil vivenciou algumas situações que exigiram atenção especial das autoridades de saúde como, os casos da microcefalia associada ao Zika vírus, que levou a Organização Mundial da Saúde (OMS) declarar ESP de importância internacional; a expansão das áreas de circulação do vírus da febre amarela, que exigiu vacinação em estados considerados não endêmicos; e a notificação de mais de 10 mil casos de sarampo em 2018, com vacinação de 11 milhões de crianças com menos de 5 anos $^{13-15}$. As relações causais entre estas situações e alterações ambientais ainda estão sendo investigadas, entretanto, servem de alerta para gestores, comunidade científica e profissionais de saúde.

\section{Desenvolvimento de políticas sobre mudanças climáticas, Redução de Risco de Desastres e Emergências em Saúde Pública}

Em 1989, a Assembleia Geral da ONU lançou a Década Internacional para a Redução de Risco de Desastres (RRD), reforçando a necessidade de redução do impacto de desastres de origem natural, em particular, para os países em desenvolvimento. Esse processo desencadeou duas iniciativas: a Estratégia de Yokohama (1994) para um mundo mais seguro e a criação da Estratégia Internacional das Nações Unidas para a Redução de Desastres - UNISDR (1999).

Em 2002, no marco de proposição das Funções Essenciais da Saúde Pública (Fesp), sistematizado pela Organização Panamericana da Saúde, a Redução do Impacto das Emergências e Desastres em Saúde surge como a décima primeira Fesp ${ }^{16}$. Em 2005, dois novos marcos internacionais das Nações Unidas reforçaram essa tendência. O primeiro, relacionado com as ESP - Regulamento Sanitário Internacional (RSI) na OMS -; e o segundo, com os desastres - Marco de Ação de Hyogo na Estratégia Internacional de Redução de Desastres (Eird), e que serviu de base para o Marco de Sendai. Esses dois acordos colocam a RRD como prioridade de ação aos Estados signatários. Foi também nesse período que a relação entre mudanças climáticas e saúde passou a ganhar cada vez maior destaque na agenda internacional.

A maior convergência entre as agendas de ESP, desastres e mudanças climáticas ocorreu a partir de 2015, com o Marco de Sendai para a RRD 2015-2030, apresentando três mudanças importantes. A primeira foi a aproximação do conceito dos desastres com ESP, reconhecendo que a RRD deve incluir as emergências definidas no RSI: origens: naturais (geológicas, hidrometeorológicas e biológicas) ou induzidas por processos humanos (degradação ambiental e perigos tecnológicos- químicas e radioativas/radiológicas).

Nesse processo, destacam-se os Princípios de Bangkok que apresentam medidas e ações em saúde visando à integração sistemática do setor nas políticas e planos de RRD, nos diferentes níveis - nacional/local, público/ privado, com o foco na redução do risco comunitário, formação e fortalecimento da capacidade de resposta nacionais e subnacionais.

A segunda foi o reconhecimento do setor saúde como contribuinte e beneficiário das estratégias de RRD. A ampliação da agenda e a conexão dos temas relacionados com os desastres e com ESP significam que não é possível assegurar a segurança sanitária e o bem-estar sem que se estruture o gerenciamento de riscos nacionais e globais de saúde, envolvendo desde os processos de prevenção de riscos de desastres e ESP até os que envolvem a preparação, o alerta precoce, as respostas e os processos de reabilitação, recuperação e reconstrução das condições de vida e saúde.

A terceira foi a incorporação das mudanças climáticas como um fator potencial de ampliar e agravar os riscos de desastres e de ESP, em sintonia com o Acordo de Paris (2015). A Agenda $2030^{17}$, com os ODS, constitui mais um passo importante de ampliação dessa agenda, 
conectando os temas relacionados aos desastres (ODS 1, 2 e 11) e às mudanças climáticas (ODS 13), com os que envolvem a necessidade de - reforçar a capacidade de todos os países, particularmente os países em desenvolvimento, para o alerta precoce, redução de riscos e gerenciamento de riscos nacionais e globais de saúde -, para assegurar uma vida saudável e promover o bem-estar para todos (ODS 3).

As tendências de integração das agendas têm como objetivo produzir transformações que, seguindo os processos de globalização, apontam para cenários de riscos globais (degradação ambiental e mudanças climáticas) envolvendo danos e doenças relacionados com os desastres e ESP com expressões locais e globais. Esses princípios, nos seus tópicos específicos, claramente apontam para a integração das agendas e temas relativos a Mudanças Climáticas e Segurança Sanitária Global, RRD e ESP, presentes e integradas aos ODS.

Outro marco importante das políticas no âmbito da saúde foi o RSI ${ }^{18}$, projetado para auxiliar a comunidade global na prevenção e resposta a riscos agudos de saúde pública que têm o potencial de avançar sobre as fronteiras geopolíticas. ESP é definida como - um evento extraordinário que constitui risco para a saúde pública de outros países, com potencial para propagação internacional - e que, em geral, requer uma resposta internacional coordenada, por sua vez, por apresentar risco à saúde pública nacional e estar relacionado, direta e indiretamente, com situações epidemiológicas (surtos ou epidemias), de desastres à população que extrapolem a capacidade de resposta do Sistema Único de Saúde (SUS). A Portaria MS/GM n ${ }^{\circ} 2.952$, de 14 de dezembro de $2011^{19}$, considerando o Decreto $\mathrm{n}^{\circ} 7.616$, de 17 de novembro de 2011, dispõe sobre a declaração de ESP de Importância Nacional (Espin); considera os eventos extraordinário citados no RSI e inclui as situações de desassistência constituindo risco para à saúde pública.

As ESP envolvem qualquer evento extraordinário que se manifeste por meio de um agravo de saúde ou uma ocorrência potencial de ameaças do ponto de vista global/local, constituindo um risco para a saúde pública, requerendo uma resposta coordenada entre os diversos níveis de gestão. Outro aspecto importante é que as ESP não se restringem à ocorrência de doenças transmissíveis, contemplando também ocorrências de natureza química, radionuclear ou decorrentes de desastres ${ }^{18}$. No âmbito global, o objetivo do RSI é ampliar as capacidades nacionais de detecção e resposta aos riscos de disseminação de doenças entre os países.

O RSI, por sua vez, tem sido fundamental na formação da Agenda Global de Segurança Sanitária, enquanto a noção de 'doença emergente' anterior do RSI destinou-se a combater doenças específicas, como a cólera ou a varíola. A versão em vigor desde 2005 inovou ao criar interfaces com acordos internacionais, fortalecendo a capacidade de atuação dos sistemas de vigilância local. Nesse contexto, emerge a vasta assimetria entre os níveis de desenvolvimento dos países signatários e a desestruturação de sua capacidade de atuação, reduzida desde os anos 1990 por meio de uma série de políticas de austeridade, tornando-as incapazes de atuar sobre as principais causas de epidemias: os determinantes sociais e ambientais da saúde ${ }^{\mathbf{2 0}}$.

\section{Do movimento reativo dos anos 1990 ao dano coletivo: a Redução de Risco de Desastres nos Objetivos de Desenvolvimento Sustentável}

O Marco de Sendai foi adotado em 18 de março de 2015 por 187 Estados-Membros das Nações Unidas após extensivas negociações na Terceira Conferência Mundial sobre RRD21. É um acordo não vinculante e voluntário e um quadro significativo para a implementação da saúde, que enfatiza o uso de abordagem multirriscos, envolvendo mecanismos de combate a todas as ameaças e perigos, inclusive tratando 
especificamente do campo de epidemias e pandemias associados ao RSI.

Considerando a experiência adquirida com a implementação do Marco de Ação de Hyogo (2005-2015) e buscando o resultado e o objetivo esperados, o Marco de Sendai enfatizou mecanismos de governança multissetorial e transdisciplinar que apoiem uma colaboração mais estreita entre os atores relevantes para prevenir, preparar e recuperar-se de desastres, bem como responder de forma eficaz.
Além de incluir ESP nas discussões sobre desastres, a Conferência Internacional sobre a Implementação dos Aspectos da Saúde do Marco de Sendai identificou sete áreas de integração da RRD nos sistemas de saúde e no setor saúde, por intermédio dos Princípios de Bangkok ${ }^{22}$. A partir da figura 1, apresentaram-se as metas e prioridades estabelecidas no Marco de Sendai correlacionadas aos princípios de Bangkok.

Figura 1. Articulação das políticas de Redução de Risco de Desastre e as Emergências de Saúde Pública

\begin{tabular}{|c|c|c|}
\hline $\begin{array}{l}\text { METAS GLOBAIS } \\
\text { (Marco de Sendai) }\end{array}$ & $\begin{array}{l}\text { PRIORIDADES DE AC̣ÃO } \\
\text { (Marco de Sendai) }\end{array}$ & $\begin{array}{l}\text { PRINCÍPIOS DE BANGKOK } \\
\begin{array}{c}\text { (Conferência Internacional sobre a Implementacãa } \\
\text { dos Aspectos da Saúde do Marco de Sendai) }\end{array}\end{array}$ \\
\hline $\begin{array}{l}\text { Reduzir substancialmente a mortalidade global } \\
\text { por desastres até 2030, com o objetivo de } \\
\text { reduzir a média de mortalidade global por } \\
100.000 \text { habitantes; }\end{array}$ & & $\begin{array}{l}\text { Promover a integração sistemática de saúde } \\
\text { nas políticas e planos nacionais e subnacionais } \\
\text { de Redução de Risco de Desastres e a inclusão } \\
\text { de programas de emergência e de gestão de }\end{array}$ \\
\hline Reduzir substancialmente o número de pessoas & & e subnacionais de saúde; \\
\hline $\begin{array}{l}\text { afetadas por desastre em todo o mundo até } \\
2030, \text { com o objetivo de reduzir a média global } \\
\text { por } 100.000 \text { habitantes; }\end{array}$ & Compreensão do risco de desastres; & $\begin{array}{l}\text { Reforçar a cooperação entre as autoridades de } \\
\text { saúde e outros parceiros relevantes visando }\end{array}$ \\
\hline $\begin{array}{l}\text { Reduzir as perdas econômicas diretas por } \\
\text { desastres até 2030, em relação ao Produto } \\
\text { Interno Bruto (PIB) global; }\end{array}$ & $\begin{array}{l}\text { Fortalecimento da governança do risco } \\
\text { de desastres para gerenciar o risco }\end{array}$ & $\begin{array}{l}\text { risco de desastres para a saúde, a implementação } \\
\text { do Regulamento Sanitário Internacional (2005) e } \\
\text { construção de sistemas de saúde resilientes; }\end{array}$ \\
\hline $\begin{array}{l}\text { Reduzir substancialmente os danos causados } \\
\text { por desastres em infraestrutura básica e a } \\
\text { interrupção de serviços básicos até 2030, pro- } \\
\text { tegendo unidades de saúde e de educação, in- }\end{array}$ & $\begin{array}{l}\text { Investimento na redução do risco de } \\
\text { desastres para a resiliência; }\end{array}$ & $\begin{array}{l}\text { Estimular investimentos públicos e privados } \\
\text { centralizados em pessoas nas emergências e } \\
\text { na Redução de Risco de Desastres, incluindo } \\
\text { nos estabelecimentos de saúde e infraestrutura; }\end{array}$ \\
\hline $\begin{array}{l}\text { Aumentar substancialmente o número de } \\
\text { países com estratégias nacionais e locais de } \\
\text { redução do risco de desastres até 2020; }\end{array}$ & $\begin{array}{l}\text { Melhoria na preparação para desastres } \\
\text { a fim de providenciar uma resposta }\end{array}$ & $\begin{array}{l}\text { Integrar a redução do risco de desastres na } \\
\text { educação e na formação em saúde e fortalecer } \\
\text { a capacitação de profissionais de saúde na } \\
\text { Redução de Risco de Desastres; }\end{array}$ \\
\hline $\begin{array}{l}\text { Intensificar a cooperação internacional com os } \\
\text { países em desenvolvimento até 2030, por meio } \\
\text { de apoio adequado e sustentável para } \\
\text { complementar suas ações nacionais na } \\
\text { implementação deste quadro; }\end{array}$ & reabilitar de maneira melhor que antes; & $\begin{array}{l}\text { Incorporar dados de mortalidade, morbidade e } \\
\text { incapacidade relacionados com desastres em } \\
\text { sistemas multirriscos de alerta, indicadores bá- } \\
\text { sicos de saúde e avaliaçốes nacionais de risco; }\end{array}$ \\
\hline $\begin{array}{l}\text { Aumentar substancialmente a disponibilidade } \\
\text { e o acesso a sistemas de alerta precoce para } \\
\text { vários perigos e as informações e avaliações } \\
\text { sobre o risco de desastres até 2030; }\end{array}$ & & $\begin{array}{l}\text { transfronteiriça, incluindo o compartilhamento de } \\
\text { informação, e ciência e tecnologia para todos } \\
\text { os perigos, incluindo perigos biológicos; }\end{array}$ \\
\hline & & $\begin{array}{l}\text { Promover a coerência e desenvolvimento das } \\
\text { políticas locais e nacionais e estratégias, estruturas } \\
\text { legais, regulamentos e arranjos institucionais; }\end{array}$ \\
\hline
\end{tabular}

Fonte: UNISDR 20,21

Em toda a estrutura do Marco de Sendai, a saúde é destacada como um resultado e uma meta, com medidas voltadas para reduzir as perdas por desastres. Quatro das sete metas globais estão diretamente relacionadas com a saúde, outras três estão indiretamente relacionadas. Há necessidade explícita de aumentar a resiliência dos sistemas nacionais de saúde, integrando a gestão de riscos de emergências e desastres aos cuidados primários, secundários e terciários, desenvolvendo a capacidade dos profissionais de saúde de 
compreendero risco de desastres e aplicar abordagens de RRD na rotina de trabalho do setor ${ }^{22}$.

Assim, autoridades e trabalhadores do setor da saúde são identificados como atores-chave para RRD e na construção da resiliência da comunidade. Com base no Marco de Hyogo, no Marco de Sendai, a saúde é um componente explícito das ações de RRD, aumentando em abrangência e especificidade, gerando mecanismo para incorporar a avaliação de risco de todos os perigos; previsão baseada em impacto; melhor capacidades de resposta e aviso prévio; gestão de recursos; criação e compartilhamento de conhecimento; construção de compromisso público e desenvolvimento de estruturas institucionais de apoio, integrada e orientada à redução de risco, envolvendo ações de prevenção, recuperação e reabilitação ${ }^{\mathbf{2 1}}$.

As tendências de integração da saúde pública, da RRD e da Adaptação às Mudanças Climáticas (AMC), sob a égide da Agenda 2030 dos ODS, têm um papel significativo de ganhos à sociedade. Com o objetivo de produzir transformações, apontam para cenários de riscos globais envolvendo danos e doenças relacionados com os desastres e ESP com expressões locais e globais, necessidade de um vínculo sistemático entre RRD e a AMC na promoção dos ODS e, finalmente, da segurança humana, essencial para enfrentar esses riscos presentes, complexos e emergentes. Isso inclui não só maximizar sinergias conceituais, mas também construir resiliência e reduzir vulnerabilidades e os riscos.

Esses riscos globais ocorrem em um complexo cenário social, ambiental e sanitário que, nos últimos anos, as questões de saúde passaram a ganhar reconhecimento e defesa de causa nos círculos de políticas internacionais. Como resultado, a saúde é um tema claramente transversal na Agenda 2015-2030, particularmente dentro do Marco de Sendai para RRD ${ }^{21}$, no Acordo de Paris sobre Mudança do Clima² e na Agenda 2030 dos ODS ${ }^{17}$. O conjunto de ações pautado nos acordos representa um passo na direção da coerência política global com referência explícita à saúde, desenvolvimento econômico e adaptação à mudança climática. Os múltiplos esforços da comunidade de saúde no processo de desenvolvimento de políticas, incluindo campanhas para escolas e hospitais seguros, ajudaram a colocar a saúde mental e física, a resiliência e bem-estar das pessoas como prioridade na agenda.

Na Resolução $n^{0} 70 / 1$ da Assembleia Geral das Nações Unidas ${ }^{17}$, de 25 de setembro de 2015, intitulada Transformando o mundo: a Agenda 2030 para o Desenvolvimento Sustentável, destaca-se o papel do planejamento e do processo de adaptação desse compromisso às realidades nacionais: a Agenda 2030 para o Desenvolvimento Sustentável estabelece um quadro de ação composto por 17 ODS, 169 metas e 232 indicadores, não vinculante aos Estados signatários, porém indivisível, pois incita a abordagem dos 17 Objetivos, evitando a fragmentação; integral, pois combina as três dimensões do desenvolvimento, a saber, econômica, social e ambiental; civilizatória, dado que propõe erradicar a extrema pobreza como um imperativo ético, colocando a dignidade e a igualdade das pessoas no centro; $\mathrm{e}$ transformador, uma vez que requer abordagens alternativas para o modo usual para alcançar o desenvolvimento sustentável.

A Agenda 2030 para o Desenvolvimento Sustentável reconhece e reafirma a necessidade urgente de reduzir o risco de desastres e seus impactos sobre os sistemas econômicos. Nesse sentido, a RRD afeta diferentes aspectos do desenvolvimento; há 17 metas diretamente relacionadas com a gestão de risco de desastres em 9 dos 17 ODS, e outras com relações indiretas que resultam no desenvolvimento de estratégias de enfrentamento. Conforme indicado no quadro 2, a partir do documento 'Disaster Risk Reduction and Resilience in the 2030 Agenda for Sustainable Development', publicado pela Estratégia Internacional de Redução de Risco de Desastres $^{\mathbf{2 4}}$, apresentam-se as seguintes metas dos ODS e do Marco de Sendai. Ressalta-se que, no âmbito da Constituição Federal de 1988, conforme apresentado no quadro 2, diversos mecanismos já constituídos conectam a Agenda 2030 para o Desenvolvimento Sustentável com os mecanismos de RRD já existentes. 
Quadro 2. Objetivo do Desenvolvimento Sustentável (ODS), Marco de Sendai, Princípios de Bangkok e marcos nacionais de redução de riscos de emergências e desastres em saúde

ODS - Meta 1: acabar com a pobreza em todas as suas formas, em todos os lugares

Meta de RRD dos ODS - Meta 1.5: Até 2030, construir a resiliência dos pobres e daqueles em situação de vulnerabilidade, e reduzir a exposição e vulnerabilidade destes a eventos extremos relacionados com o clima e outros choques e desastres econômicos, sociais e ambientais.

\begin{tabular}{|c|c|}
\hline \multicolumn{2}{|r|}{ Metas de redução de risco (Marco de Sendai e Princípios de Bangkok) } \\
\hline 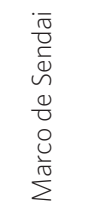 & $\begin{array}{l}\text { Reduzir as perdas econômicas diretas por desastres até 2030, } \\
\text { em relação ao Produto Interno Bruto (PIB) global; } \\
\text { Reduzir substancialmente os danos causados por desastres em } \\
\text { infraestrutura básica e a interrupção de serviços básicos até } \\
\text { 2030, protegendo unidades de saúde e de educação, inclusive } \\
\text { por meio do aumento de sua resiliência. }\end{array}$ \\
\hline 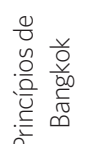 & $\begin{array}{l}\text { Promover a integração sistemática de saúde nas políticas e pla- } \\
\text { nos nacionais e subnacionais de redução do risco de desastres e } \\
\text { a inclusão de programas de emergência e de gestão de riscos de } \\
\text { desastres nas estratégias nacionais e subnacionais de saúde. }\end{array}$ \\
\hline
\end{tabular}

\section{Marco Nacional de Redução de Risco de Desastre}

CF/88, art. 3o, inciso III - Erradicar a pobreza e a marginalização e reduzir a desigualdade social e regional.

Planos Setoriais de Mitigação e Adaptação às Mudanças do Clima (PSMC) Diretriz 6 - Formulação de políticas específicas que aumentem a resiliência dos grupos sociais de maior vulnerabilidade à mudança do clima junto às populações do campo, das águas, da floresta, aos indígenas e às populações de rua. Diretriz 8 -Fortalecimento da Vigilância em Saúde para a identificação dos riscos à saúde humana associados à mudança do clima, com vistas a subsidiar a adoção de medidas de adaptação no âmbito do SUS.

\section{ODS - Meta 2: acabar com a fome, alcançar a segurança alimentar e melhoria da nutrição e promover a agricultura sustentável}

Meta de RRD dos ODS - Meta 2.4: Até 2030, garantir sistemas sustentáveis de produção de alimentos e implementar práticas agrícolas resilientes, que aumentem a produtividade e a produção, que ajudem a manter os ecossistemas, que fortaleçam a capacidade de adaptação às mudanças do clima, às condições meteorológicas extremas, secas, inundações e outros desastres, e que melhorem progressivamente a qualidade da terra e do solo.

\begin{tabular}{|c|c|}
\hline $\begin{array}{l}\bar{\pi} \\
0 \\
\frac{0}{0} \\
\sim \\
0 \\
0 \\
0 \\
0 \\
0 \\
\stackrel{0}{0}\end{array}$ & $\begin{array}{l}\text { Reduzir as perdas econômicas diretas por desastres até 2030, } \\
\text { em relação ao PIB global. }\end{array}$ \\
\hline 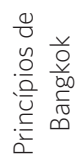 & $\begin{array}{l}\text { Promover a coerência e desenvolvimento das políticas locais e } \\
\text { nacionais e estratégias, estruturas legais, regulamentos e arran- } \\
\text { jos institucionais; }\end{array}$ \\
\hline
\end{tabular}

\section{Marco Nacional de Redução de Risco de Desastre}

CF/88, art. 6 - São direitos sociais a educação, a saúde, a alimentação, o trabalho, a moradia, o transporte, o lazer, a segurança, a previdência social, a proteção à maternidade e à infância, a assistência aos desamparados, na forma desta Constituição.

Lei no 11.346/2006 - Direito de todos ao acesso regular e permanente a alimentos de qualidade, em quantidade suficiente, sem comprometer 0 acesso a outras necessidades essenciais.

Decreto no 7.272/2010 (Política Nacional de Segurança Alimentar e Nutricional - PNSAN);

Lei no 8.171/1991 - Prevê os recursos e estabelece as ações e instrumentos da política agrícola: art. 3ำ, incisos III e IV (agricultura sustentável).

ODS - Objetivo 3: assegurar uma vida saudável e promover o bem-estar para todos, em todas as idades

Meta de RRD dos ODS - Meta 3.d: Reforçar a capacidade de todos os países, particularmente os países em desenvolvimento, para o alerta precoce, redução de riscos e gerenciamento de riscos nacionais e globais de saúde.

\begin{tabular}{|c|c|c|}
\hline \multicolumn{2}{|r|}{ Metas de redução de risco (Marco de Sendai e Princípios de Bangkok) } & \multirow[b]{2}{*}{$\begin{array}{l}\text { Marco Nacional de Redução de Risco de Desastre } \\
\text { CF/88, art. 30, inciso iv (bem-estar); CF/88, art. 60 (saúde) } \\
\text { Lei no 8.080, de } 19 \text { de setembro de 1990. } \\
\text { Decreto no 7.508, de } 28 \text { de junho de } 2011 \text { - regulamenta a Lei no 8.080, } \\
\text { de } 19 \text { de setembro de 1990, para dispor sobre a organização do Sistema } \\
\text { Único de Saúde - SUS, o planejamento da saúde, a assistência à saúde e } \\
\text { a articulação interfederativa, e dá outras providências. } \\
\text { Decreto no } 7.616 \text {, de } 17 \text { de novembro de 2011. Dispõe sobre a declaração } \\
\text { de Emergência em Saúde Pública de Importância Nacional - Espin e } \\
\text { institui a Força Nacional do Sistema Único de Saúde - FN-SUS. } \\
\text { Portaria no 2.952, de } 14 \text { de dezembro de } 2011 \text { - regulamenta o Decreto } \\
\text { no } 7.616 . \\
\text { Resolução no 588, de } 12 \text { de julho de } 2018 \text { - instituí a Política Nacional de } \\
\text { Vigilância em Saúde (PNVS). } \\
\text { Centro de informações estratégias e respostas em vigilância em saúde } \\
\text { (Cievs) }\end{array}$} \\
\hline 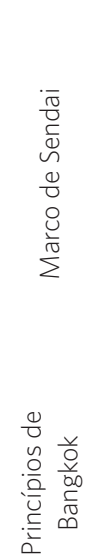 & $\begin{array}{l}\text { pessoas afetadas por } \\
\text { usados o objetivo de reduzir a } \\
\text { serviços básicos até } \\
\text { de educação, inclusive } \\
\text {; } \\
\text { ilidade e o acesso a } \\
\text { perigos e as informações } \\
\text { até } 2030 \text {; } \\
\text { aúde nas políticas e pla- } \\
\text { a e do risco de desastres e } \\
\text { ubnacionais de saúde; }\end{array}$ & \\
\hline
\end{tabular}


Quadro 2. (cont.)

Estimular investimentos públicos e privados centralizados em pessoas nas emergências e na redução do risco de desastres, incluindo nos estabelecimentos de saúde e infraestrutura; Promover e apoiar a colaboração intersetorial, transfronteiriça, incluindo o compartilhamento de informação, e ciência e tecnologia para todos os perigos, incluindo perigos biológicos;
Portaria de consolidação GM/MS no 1, de 28 de setembro de 2017 - Consolidação das normas sobre os direitos e deveres dos usuários da saúde, a organização e o funcionamento do sistema único de saúde. Portaria GM/MS no 3.733, de 22 de novembro de 2018 - Estabelece a relação nacional de medicamentos essenciais - rename 2018 no âmbito do Sistema Único de Saúde (SUS) por meio da atualização do elenco de medicamentos e insumos da Relação Nacional de Medicamentos Essenciais - Rename 2017.

Portaria no 1.555/GM/MS, de 30 de julho de 2013 - Dispõe sobre as normas de financiamento e de execução do Componente Básico da Assistência Farmacêutica no âmbito do Sistema Único de Saúde (SUS). Portaria no 704/GM/MS, de 8 de março de 2017 - Define a lista de produtos estratégicos para o Sistema Único de Saúde (SUS), nos termos dos anexos a esta Portaria

\section{ODS - Objetivo 4: assegurar a educação inclusiva e equitativa e de qualidade, e promover oportunidades de aprendizagem ao longo da vida para todos} Meta de RRD dos ODS - Meta 4.7: Até 2030, garantir que todos os alunos adquiram conhecimentos e habilidades necessárias para promover o desenvolvimento sustentável, inclusive, entre outros, por meio da educação para o desenvolvimento sustentável e estilos de vida sustentáveis, direitos humanos, igualdade de gênero, promoção de uma cultura de paz e não-violência, cidadania global, e valorização da diversidade cultural e da contribuição da cultura para o desenvolvimento sustentável.

Meta 4.a: Construir e melhorar instalações físicas para a educação, apropriadas para crianças e sensíveis às deficiências e ao gênero e que proporcionem ambientes de aprendizagem seguros, não violentos, inclusivos e eficazes para todos.

\begin{tabular}{|c|c|}
\hline \multicolumn{2}{|r|}{ Metas de redução de risco (Marco de Sendai e Princípios de Bangkok) } \\
\hline 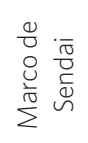 & $\begin{array}{l}\text { Integrar a redução do risco de desastres na educação e na for- } \\
\text { mação em saúde e fortalecer a capacitação de profissionais de } \\
\text { saúde na redução do risco de desastres. }\end{array}$ \\
\hline 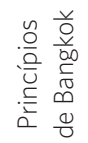 & $\begin{array}{l}\text { Integrar a redução do risco de desastres na educação e na for- } \\
\text { mação em saúde e fortalecer a capacitação de profissionais de } \\
\text { saúde na redução do risco de desastres. }\end{array}$ \\
\hline
\end{tabular}

Marco Nacional de Redução de Risco de Desastre

CF/88, art. 6ㅇ (São direitos sociais a educação, a saúde, a alimentação, o trabalho, a moradia, o transporte, o lazer, a segurança, a previdência social, a proteção à maternidade e à infância, a assistência aos desamparados).

ODS - Meta 6: assegurar a disponibilidade e gestão sustentável da água e saneamento para todas e todos

Meta de RRD dos ODS - Meta 6.6: Até 2020, proteger e restaurar ecossistemas relacionados com a água, incluindo montanhas, florestas, zonas úmidas, rios, aquíferos e lagos.

\section{Metas de redução de risco (Marco de Sendai e Princípios de Bangkok) \\ ه Reduzir substancialmente os danos causados por desastres em ○ $\overline{0}$ infraestrutura básica e a interrupção de serviços básicos até

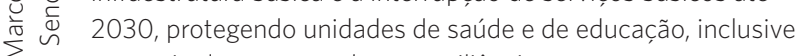 por meio do aumento de sua resiliência.}

Estimular investimentos públicos e privados centralizados em pessoas nas emergências e na redução do risco de desastres, incluindo nos estabelecimentos de saúde e infraestrutura; Reforçar a cooperação entre as autoridades de saúde e outros parceiros relevantes visando fortalecer a capacidade do país para a gestão do risco de desastres para a saúde, a implementação do Regulamento Sanitário Internacional (2005) e construção de sistemas de saúde resilientes;

Promover a integração sistemática de saúde nas políticas e planos nacionais e subnacionais de redução do risco de desastres e a inclusão de programas de emergência e de gestão de riscos de desastres nas estratégias nacionais e subnacionais de saúde.

\section{Marco Nacional de Redução de Risco de Desastre}

Lei no 9.433/1997, art. 20 (água); Lei no 11.445/2007, art. 20 (saneamento). Planos Setoriais de Mitigação e Adaptação às Mudanças do Clima (PSMC) - Diretriz 7 - Fortalecimento da implantação das políticas nacionais de saneamento e de saúde, visando à universalização do acesso à água potável e ao saneamento.

Política Nacional de Vigilância em Saúde (PNVS) (Resolução no 588, de 12 de julho de 2018)

Portaria no 2.914, de 12 de dezembro de 2011. Dispõe sobre os procedimentos de controle e de vigilância da qualidade da água para consumo humano e seu padrão de potabilidade.

Portaria de Consolidação no 5 de 28/09/2017. 
Quadro 2. (cont.)

ODS - Meta 9: construir infraestruturas resilientes, promover a industrialização inclusiva e sustentável e fomentar a inovação

Meta de RRD dos ODS - Meta 9.1: Desenvolver infraestrutura de qualidade, confiável, sustentável e resiliente, incluindo infraestrutura regional e transfronteiriça, para apoiar o desenvolvimento econômico e o bem-estar humano, com foco no acesso equitativo e a preços acessíveis para todos. Meta 9.a: Facilitar o desenvolvimento de infraestrutura sustentável e resiliente em países em desenvolvimento, por meio de maior apoio financeiro, tecnológico e técnico aos países africanos, aos países de menor desenvolvimento relativo, aos países em desenvolvimento sem litoral e aos pequenos Estados insulares em desenvolvimento

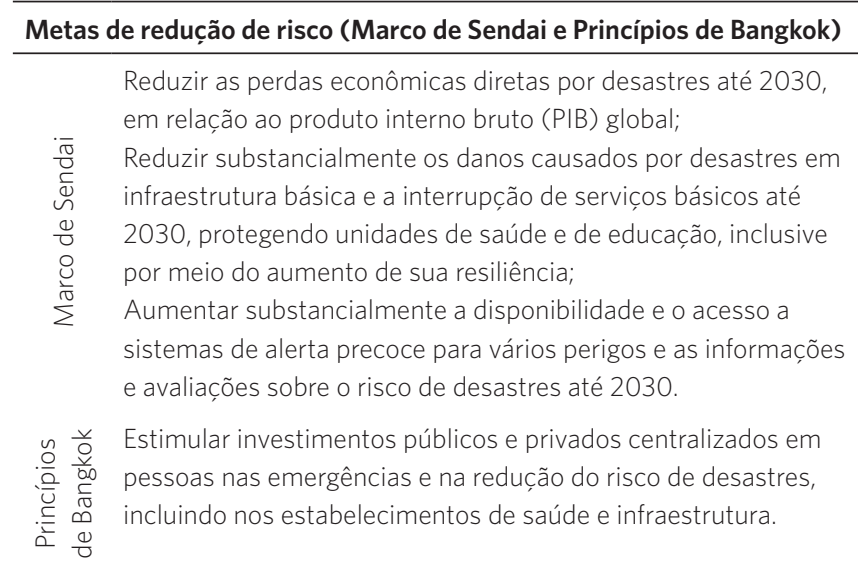

\section{Marco Nacional de Redução de Risco de Desastre}

Lei no 10.257/2001, art. 2ㅇ, inc. I (cidades sustentáveis).

Planos Setoriais de Mitigação e Adaptação às Mudanças do Clima (PSMC) - Diretriz 5 - Fomento e promoção de estabelecimentos de saúde sustentáveis, resilientes e seguros no âmbito do SUS e da saúde suplementar para a continuidade dos serviços de saúde nos cenários de desastres, insegurança hídrica e energética, bem como a promoção dos princípios do desenvolvimento sustentável nos diversos seguimentos do setor saúde, e contribuir para a redução da emissão de Gases de Efeito Estufa (GEE).

\section{ODS - Meta 11: tornar as cidades e os assentamentos humanos inclusivos, seguros, resilientes e sustentáveis}

Meta de RRD dos ODS - Meta 11.1: Até 2030, garantir o acesso de todos a habitação segura, adequada e a preço acessível, e aos serviços básicos e urbanizar as favelas.

Meta 11.3: Até 2030, aumentar a urbanização inclusiva e sustentável, e a capacidade para o planejamento e a gestão participativa, integrada e sustentável dos assentamentos humanos, em todos os países.

Meta 11.4: Fortalecer esforços para proteger e salvaguardar o patrimônio cultural e natural do mundo.

Meta 11.5: Até 2030, reduzir significativamente o número de mortes e o número de pessoas afetadas por desastres e diminuir substancialmente as perdas econômicas diretas causadas por elas em relação ao produto interno bruto global, incluindo os desastres relacionados à água, com o foco em proteger os pobres e as pessoas em situação de vulnerabilidade.

Meta 11.b: Até 2020, aumentar substancialmente o número de cidades e assentamentos humanos adotando e implementando políticas e planos integrados para a inclusão, a eficiência dos recursos, mitigação e adaptação à mudança do clima, a resiliência a desastres; e desenvolver e implementar, de acordo com o Marco de Sendai para a Redução do Risco de Desastres 2015-2030, o gerenciamento holístico do risco de desastres em todos os níveis. Meta 11.c: Apoiar os países menos desenvolvidos, inclusive por meio de assistência técnica e financeira, para construções sustentáveis e robustas, utilizando materiais locais.

\begin{tabular}{|c|c|}
\hline \multicolumn{2}{|r|}{ Metas de redução de risco (Marco de Sendai e Princípios de Bangkok) } \\
\hline $\begin{array}{l}\bar{\pi} \\
\overline{0} \\
\tilde{D} \\
\sim \\
0 \\
0 \\
0 \\
0 \\
\frac{0}{\pi} \\
\end{array}$ & $\begin{array}{l}\text { Reduzir substancialmente o número de pessoas afetadas por } \\
\text { desastre em todo o mundo até 2030, com o objetivo de reduzir a } \\
\text { média global por } 100.000 \text { habitantes; } \\
\text { Reduzir as perdas econômicas diretas por desastres até } 2030 \text {, } \\
\text { em relação ao Produto Interno Bruto (PIB) global; } \\
\text { Reduzir substancialmente os danos causados por desastres em } \\
\text { infraestrutura básica e a interrupção de serviços básicos até } \\
\text { 2030, protegendo unidades de saúde e de educação, inclusive } \\
\text { por meio do aumento de sua resiliência; } \\
\text { Aumentar substancialmente a disponibilidade e o acesso a } \\
\text { sistemas de alerta precoce para vários perigos e as informações } \\
\text { e avaliações sobre o risco de desastres até } 2030 \text {. }\end{array}$ \\
\hline
\end{tabular}

\section{Marco Nacional de Redução de Risco de Desastre}

CF/88, art. 6을 (segurança); Lei 10.257/2001, art. 2ำ, inc. I (cidades sustentáveis).

Política Nacional de Proteção e Defesa Civil (PNPDEC). 
Quadro 2. (cont.)

Estimular investimentos públicos e privados centralizados em

․․ pessoas nas emergências e na redução do risco de desastres,

$\underset{0}{\frac{2}{0}}$ incluindo nos estabelecimentos de saúde e infraestrutura;

Incorporar dados de mortalidade, morbidade e incapacidade

$\frac{\otimes}{0}$ relacionados com desastres em sistemas multirriscos de alerta,

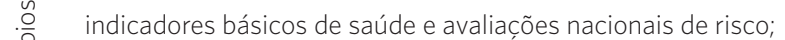

Promover a coerência e desenvolvimento das políticas locais e

¿ nacionais e estratégias, estruturas legais, regulamentos e arran-

jos institucionais.

ODS - Meta 13: tomar medidas urgentes para combater a mudança climática e seus impactos

Meta de RRD dos ODS - Meta 13.1: Reforçar a resiliência e a capacidade de adaptação a riscos relacionados ao clima e às catástrofes naturais em todos os países.

Meta 13.2: Integrar medidas da mudança do clima nas políticas, estratégias e planejamentos nacionais.

Meta 13.3: Melhorar a educação, aumentar a conscientização e a capacidade humana e institucional sobre mitigação global do clima, adaptação, redução de impacto, e alerta precoce à mudança do clima.

Meta 13.a: Implementar o compromisso assumido pelos países desenvolvidos partes da Convenção Quadro das Nações Unidas sobre Mudança do Clima para a meta de mobilizar conjuntamente US $\$ 100$ bilhões por ano até 2020, de todas as fontes, para atender às necessidades dos países em desenvolvimento, no contexto de ações significativas de mitigação e transparência na implementação; e operacionalizar plenamente o Fundo Verde para o Clima, por meio de sua capitalização, o mais cedo possível.

Meta 13.b: Promover mecanismos para a criação de capacidades para o planejamento relacionado à mudança do clima e à gestão eficaz, nos países menos desenvolvidos, inclusive com foco em mulheres, jovens, comunidades locais e marginalizadas.

\section{Metas de redução de risco (Marco de Sendai e Princípios de Bangkok) Marco Nacional de Redução de Risco de Desastre}

Convenção Quadro das Nações Unidas sobre Mudança do Clima (UNFCCC), ratificada pelo Brasil em 1994.

Decreto no 3.515 - Fórum Brasileiro de Mudanças Climáticas. Comissão Mista Permanente sobre Mudanças Climáticas,

Comissão Gestora e o Comitê Executivo de Clima e Saúde, por meio da Portaria GM/MS № 3.244/2011.

Plano Nacional de Adaptação à Mudança do Clima (PNAMC) (Portaria no 150 de 10 de maio de 2016).

Planos Setoriais de Mitigação e Adaptação às Mudanças do Clima (PSMC), (Decreto no 7.390 de 2010).

\section{ODS - Meta 14: conservação e uso sustentável dos oceanos, dos mares e dos recursos marinhos para o desenvolvimento sustentável}

Meta de RRD dos ODS - Meta 14.2: Até 2020, gerir de forma sustentável e proteger os ecossistemas marinhos e costeiros para evitar impactos adversos significativos, inclusive por meio do reforço da sua capacidade de resiliência, e tomar medidas para a sua restauração, a fim de assegurar oceanos saudáveis e produtivos.

Metas de redução de risco (Marco de Sendai e Princípios de Bangkok)

Marco Nacional de Redução de Risco de Desastre

CF/88, art. 225 (meio ambiente); Convenção das Nações Unidas sobre o

Direito do Mar, ratificada pelo Brasil em 1988.

ODS - Meta 15: proteger, recuperar e promover o uso sustentável dos ecossistemas terrestres, gerir de forma sustentável as florestas, combater a desertificação, deter e reverter a degradação da terra e deter a perda de biodiversidade

Meta de RRD dos ODS - Meta 15.1: Até 2020, assegurar a conservação, recuperação e uso sustentável de ecossistemas terrestres e de água doce interiores e seus serviços, em especial, florestas, zonas úmidas, montanhas e terras áridas, em conformidade com as obrigações decorrentes dos acordos internacionais.

Meta 15.2: Até 2020, promover a implementação da gestão sustentável de todos os tipos de florestas, deter o desmatamento, restaurar florestas degradadas e aumentar substancialmente o florestamento e o reflorestamento.

Meta 15.3: Até 2030, combater a desertificação, e restaurar a terra e o solo degradado, incluindo terrenos afetados pela desertificação, secas e inundações, e lutar para alcançar um mundo neutro em termos de degradação do solo. 
Quadro 2. (cont.)

Meta 15.4: Até 2030, assegurar a conservação dos ecossistemas de montanha, incluindo a sua biodiversidade, para melhorar a sua capacidade de proporcionar benefícios, que são essenciais para o desenvolvimento sustentável.

Meta 15.9: Até 2020, integrar os valores dos ecossistemas e da biodiversidade ao planejamento nacional e local, nos processos de desenvolvimento, nas estratégias de redução da pobreza, e nos sistemas de contas.

CF/88, art. 225 (meio ambiente); Convenção das Nações Unidas sobre Diversidade Biológica, ratificada pelo Brasil em 1994; Convenção das Nações Unidas para o Combate à Desertificação e Mitigação dos Efeitos da Seca, ratificada pelo Brasil em 1997. Lei no 13.123, de 20 de maio de 2015.

Regulamenta o inciso II do $\$ 10$ e o $\$$ 4으 do art. 225 da Constituição Federal, o Artigo 1, a alínea j do Artigo 8, a alínea c do Artigo 10, o Artigo 15 e os §§ 3ำ e 4ำ do Artigo 16 da Convenção sobre Diversidade Biológica, promulgada pelo Decreto no 2.519, de 16 de março de 1998; dispõe sobre o acesso ao patrimônio genético, sobre a proteção e o acesso ao conhecimento tradicional associado e sobre a repartição de benefícios para conservação e uso sustentável da biodiversidade; revoga a Medida Provisória no $2.186-16$, de 23 de agosto de 2001; e dá outras providências.

Decreto no 8.772 , de 11 de maio de 2016

Regulamenta a Lei no 13.123, de 20 de maio de 2015, que dispõe sobre o acesso ao patrimônio genético, sobre a proteção e o acesso ao conhecimento tradicional associado e sobre a repartição de benefícios para conservação e uso sustentável da biodiversidade.

\section{Problemas globais, expressões locais: ações necessárias para a ampliação do Sistema Nacional de Redução de Riscos à Saúde}

Segundo os dados da Secretaria Nacional de Proteção e Defesa Civil26, em 20 anos, os desastres ocorridos no Brasil afetaram a vida de mais de 96 milhões de pessoas. Em todo o território nacional, 92,8\% dos municípios de grande porte (>500 mil habitantes) já registraram desastres, enquanto na classe de municípios de pequeno porte (com até 5 mil habitantes), foram registrados $18 \%{ }^{27}$. As ESP envolvendo doenças transmissíveis e infecciosas somam-se a esse cenário; desde 2018, o Brasil enfrenta a reintrodução do vírus do sarampo, com a ocorrência de surtos em 11 Estados, com um total de 10.326 casos confirmados ${ }^{28}$. Sem considerar que os novos cenários de risco experimentados nos desastres tecnológicos envolvendo as barragens de mineração, citados nos parágrafos anteriores, ambos no estado de Minas Gerais, tenham sido solucionados. São diversas as dificuldades de recuperação das formas de reprodução social enfrentadas pelas populações afetadas, coadunando vulnerabilidade com problemas ambientais complexos, envolvendo risco química e biológico ${ }^{3}$.

Diante dos desafios expostos, ocorre a necessidade de ampliação do Sistema Nacional de Redução de Riscos à Saúde, capaz de responder aos principais desafios preconizados pela agenda 2015-2030 da ONU e apto a monitorar riscos e fortalecer as ações de resposta em saúde pública. Para tanto, apresentamos seis recomendações necessárias à ampliação desse sistema. 


\section{Reforçar as ações de gestão de risco e o cuidado integral à saúde}

$\mathrm{O} \mathrm{RSI}^{29}$ trouxe uma nova perspectiva preventiva para saúde pública - o olhar voltado para os fatores de risco que podem gerar surtos e epidemias ${ }^{20}$. Nessa perspectiva, gerir riscos à saúde exige refletir a partir de três importantes pontos: primeiro, sobre modelos de assistência que possam promover o cuidado integral à saúde; segundo, sobre sistemas de alerta adequados à diversidade do nosso país; terceiro, sobre fortalecimento do SUS na esfera municipal.

A Lei ${ }^{0}$ 8.080/1990 do Ministério da Saúde ${ }^{30}$, a Lei Orgânica da Saúde, dispõe sobre as condições para a promoção, proteção e recuperação da saúde, a organização e o funcionamento dos serviços correspondentes e dá outras providências. De acordo com o art. 18 dessa lei, é competência do setor saúde planejar, organizar, controlar e avaliar as ações e os serviços de saúde pertinente. A descentralização e a integralidade da atenção à saúde destinam competência ao ente federativo municipal para estar preparado e organizado para direcionar e executar ações de prevenção, mitigação, preparação, resposta, reabilitação e reconstrução. Segundo Teixeira et al. ${ }^{\mathbf{3 1}}$, essas estratégias devem ser baseadas nos princípios do SUS, especialmente, considerando a universalidade do cuidado, a descentralização das ações e a atenção integral à saúde da população, sem, contudo, deixar de subsidiar a formulação de políticas, bem como a organização dos serviços e ações de saúde, por meio dos conselhos de participação social.

Segundo Teixeira et al. ${ }^{\mathbf{3 2}}$, tal prática vem permitindo conferir ao País um sistema de uniformidade técnica e operacional, fluxos de informações contínuos entre as distintas esferas de gestão, integração da rede de serviços que hoje compõe o Sistema Nacional de Vigilância em Saúde (SNVS) com as demais áreas da rede de atenção à saúde. Além dessa reorganização, há que se destacar outras iniciativas do SUS, como a ampliação do acesso ao tratamento para diversas doenças transmissíveis que passaram a ser oferecidos à população de forma universal, mas também por estabelecer um conjunto de políticas sociais e econômicas que contribuíram efetivamente para a redução do risco de doenças e outros agravos ${ }^{33}$.

As ESP, assim como os desastres, configuram-se situações que demandam o emprego imediato de medidas de prevenção, de controle, de contenção de riscos em situações de caráter epidemiológico, de caráter sanitário, de caráter ambiental, ou ainda situações que provoquem colapso da assistência à saúde da população ${ }^{31}$. Isso exige criar, implantar e testar sistemas de alerta para desastres e outras ESP contendo eixos centrais conhecidos, porém com algum grau de adaptação local - regional.

A Política Nacional de Vigilância em Saúde (PNVS) - Resolução ${ }^{0} 588$, de 12 de julho de $2018^{34}$, considera a necessidade de dispor de equipes aptas a atuar no âmbito da vigilância em saúde, com capacidade de analisar contextos e identificar fatores de risco territoriais e à saúde, organizar, monitorar e avaliar os processos de trabalho relacionados com os desastres e com as ESP. Essa política tem o objetivo de desenvolver um processo contínuo e sistemático de coleta, consolidação, análise de dados e disseminação de informações sobre eventos com potencial de riscos e danos à saúde. Nesse sentido, o planejamento e a implementação devem contar com ações de regulação, intervenção e atuação sobre os condicionantes e determinantes da saúde, visando à proteção, à promoção, à prevenção e ao controle de riscos de agravos e doenças.

O papel do setor saúde na redução de riscos envolve ações específicas de diferentes setores em diferentes temporalidades, principalmente ligados a atenção e vigilância em saúde. essas ações devem ser coordenadas e integradas em um processo único de cuidado e não se limitando à fase de resposta imediata. Envolve todas as etapas da gestão por processo na qual a saúde pública tem claras atribuições em curto, médio e longo prazos, em todas as esferas de gestão do SUS. 


\section{Intensificar planejamentos integrados por processo}

Um sistema nacional para redução de riscos à saúde requer o estabelecimento de ações conjuntas entre diferentes setores para reduzir a exposição da população, fortalecer e ampliar a capacidade de preparação e resposta dos serviços de saúde ${ }^{35}$.

Os serviços públicos, em geral, possuem um sistema organizacional composto por áreas específicas de atuação com objetivos e metas fragmentadas. Cada serviço empenha-se em sua especificidade e quase sempre se articula com os demais setores de um mesmo serviço de forma vertical, respeitando hierarquias. Narváez et al. ${ }^{36}$ propõem um sistema de gestão de risco por processo, quebrando a lógica setorizada de atuação e promovendo uma articulação horizontal entre diferentes setores. Nessa perspectiva, o foco das ações está no processo, e somente quando todos os setores cumprem seu papel é que a meta pode ser considerada cumprida.

É importante destacar que cada setor deve reconhecer seu papel diante da redução de riscos e ser reconhecido pelos seus pares. Essa mudança de perspectiva pode contribuir para a gestão de risco, principalmente nas ações que exigem maior integração entre diferentes atores.

\section{Preparar a força de trabalho}

Um sistema nacional de redução de riscos exige ainda técnicos preparados em diferentes níveis de formação e especialidades para operacionalizá-lo. Portanto, será necessário apoio à capacitação de quadros profissionais na área da saúde preparados para o enfrentamento dos impactos imediatos de eventos provocados por mudanças climáticas, desastres e ESP, bem como para reabilitação e prevenção de situações que envolvem riscos futuros.

Nesse sentido, em novembro de 2011, por meio do Decreto $\mathrm{n}^{0} \mathbf{7 . 6 1 6 ^ { 1 9 }}$, e também como uma resposta institucional aos cenários de
ESP e aos desastres, bem como os envolvendo emergências provocadas pela desassistência, o Estado brasileiro ampliou a capacidade de vigilância e resposta em todo o território nacional, dispondo de regulamentação sobre a Espin, e instituindo a Força Nacional do Sistema Único de Saúde (FN-SUS). A FN-SUS é um programa de cooperação voltado à execução de medidas de prevenção, assistência e repressão a situações epidemiológicas, de desastres ou de desassistência à população quando esgotada a capacidade de resposta do estado ou do município ${ }^{35}$.

No entanto, no Brasil, não existe em nível nacional a inserção de conteúdo sobre RRD nas Diretrizes Curriculares na formação de pessoal na área da saúde, ou ainda, programas de educação continuada padronizados e específicos para profissionais de saúde. Em contrapartida, há oferta de cursos presenciais e a distância oferecidos por diferentes instituições, muitas vezes com incentivo e parceria do próprio Ministério da Saúde.

Estruturar programas de formação com perspectiva de formar para além da resposta imediata é um requisito importante. A proposta pedagógica deve levar em conta uma formação voltada para o processo de gestão de risco, abordando todas as suas fases (prevenir riscos futuros, reduzir riscos existentes, preparar as respostas, responder aos desastres e reabilitar as condições de vida, recuperar e reconstruir comunidades). Associado a isso, a formação para um sistema nacional de redução de risco deve contemplar os princípios básicos do SUS, como universalidade, equidade e integralidade ${ }^{32}$.

\section{Investir em infraestrutura resiliente}

A infraestrutura e os equipamentos de saúde sofrem danos materiais em eventos decorrentes dos efeitos das a mudanças do clima ou desastres. Os danos a instalações públicas de saúde causados por desastres no Brasil, 
entre 2010 e 2014, chegaram a R $\$ 1,2$ bilhão. No mesmo período, foram investidos $\mathrm{R} \$ 4$ bilhões em recursos públicos na aquisição de materiais permanentes e construção de edificações para a saúde, ou seja, o equivalente a $30 \%$ do valor total investido foi perdido ${ }^{37}$.

Esses equipamentos públicos de saúde fazem parte do sistema de proteção social, ao qual uma sociedade vai recorrer, tanto durante o momento de emergência quanto nas fases posteriores, buscando recuperar os danos e retornar à situação de normalidade ${ }^{38}$.

No Brasil, essa realidade exige, além de medidas mais rigorosas na construção de novas unidades, uma reconstrução com vistas a estruturas mais resistentes. A fase de reconstrução deveria ser uma oportunidade para isso, incluindo melhores serviços de abastecimento de água, fontes alternativas de energia, ou seja, adaptação e redução de vulnerabilidades desses sistemas. Na reconstrução, deveriam ser eliminados os principais fatores de risco, dando oportunidade à comunidade afetada de condições melhores que as anteriores e, consequentemente, estando mais preparada em eventos futuros ${ }^{39}$.

A incorporação da abordagem de resiliência climática nos sistemas de saúde contribuiria para assegurar a performance do sistema e a sustentabilidade e maximização dos investimentos financeiros em saúde ${ }^{29}$.

\section{Produzir tecnologia e inovação}

Os cenários de riscos relacionados com a saúde provocados pelas mudanças climáticas, desastres e ESP tendem a se tornar mais dinâmicos e complexos, exigindo inovação na pesquisa e tecnologias para lidar com novos problemas, como, por exemplo, a microcefalia associada ao Zika vírus. É preciso também inovação para lidar com problemas já conhecidos, mas que se apresentam de forma diferenciada, na qual ações antes eficientes perdem a capacidade de resolução. As pesquisas devem ter como prioridade oferecer subsídios aos serviços de saúde para lidar com novos fatores de risco presentes em cenários atuais, agravados pelas condições de vulnerabilidade, mas também com cenários prospectivos.

Em relação às Américas, destaca-se a importância de investir em estudos sobre vigilância em saúde, detecção e alerta em relação a zoonoses e doenças transmissíveis comuns ao homem e aos animais como potenciais ESP de Interesse Internacional para construir uma base de evidências para futuros esforços de redução de risco de infecção na interface saúde animal/ saúde humana. Essa interface deve ser analisada, sobretudo, no âmbito dos desastres, que agravam ou potencializam as formas de transmissão $0^{40}$.

São necessários ainda recursos tecnológicos e ferramentas apropriadas para detecção precoce das principais doenças por tipo de desastre. Em uma experiência lançada pela OMS em regiões que necessitam de ajuda humanitária, foram distribuídos equipamentos que oferecem suporte ao funcionamento do sistema, como celulares, baterias, geradores solares, laptops, entre outros, para captar informações in loco. Essas informações são enviadas imediatamente para um sistema central, em que os dados são usados para gerar relatórios em tempo real que permitem uma resposta rápida a doenças antes que elas tenham tempo de se propagar41.

O envolvimento de instituições acadêmicas em resposta aos desastres é influenciado por vários fatores, incluindo possibilidade de recursos disponíveis e de relações preexistentes de cooperação com serviços de saúde pública. Instituições acadêmicas possuem um gama de recursos relevantes e abordagens inovadoras para a preparação a desastres, a natureza multidisciplinar delas pode contribuir para o desenvolvimento do pensamento interdisciplinar valioso quando se trata de soluções para problemas desafiadores ${ }^{42}$. No Brasil, esse potencial precisa ser levantado, analisado e sistematizado para melhor definir o papel destas instituições para estabelecimento de parcerias sólidas de cooperação com os serviços de saúde. 


\section{Criar fundo de financiamento}

A criação de um Fundo de financiamento específico para elaborar, apoiar e promover ações e pesquisas sobre redução de riscos à saúde justifica-se pela necessidade de expandir a faixa geográfica de programas de vigilância e controle para doenças infecciosas sensíveis ao clima, buscando a melhoria dos serviços de saúde para responder, adaptar-se e tornar-se preparado a eventos climáticos extremos. Recursos adicionais serão também necessários em diversos setores para atingir metas de saúde, como implementação de projetos de saneamento, programas de segurança alimentar e nutricional durante as secas, construção e reconstrução de infraestrutura resiliente.

Recursos captados devem ser utilizados a partir de prioridades definidas por critérios técnicos, geridos por mecanismos que garantam a transparência da aplicação dos recursos e pautados em políticas que comprometam gestores atuais e futuros com a criação e implantação de um Sistema Nacional de Redução de Riscos à Saúde provocados pelas mudanças climáticas, desastres e ESP.

\section{Considerações finais}

Procuramos, neste artigo, evidenciar avanços e explicitar desafios a serem superados em cenários prospectivos e incertos relativos a mudanças do clima, desastres e ESP. Por um lado, nos últimos anos, ocorreu a implementação e o fortalecimento de instituições e políticas públicas voltadas à redução de risco, com a ampliação dos espaços institucionais e a atuação intersetorial, resultando na melhoria de indicadores de saúde, nas condições de vida e redução da mortalidade. Por outro, essas conquistas ocorrem em um contexto de redução dos investimentos públicos e do papel do estado em assegurar a realização dos direitos sociais e ambientais básicos. Assim, a mudança do cenário nacional para uma efetiva redução de riscos não está próxima, tampouco assegurada, carece ainda, no âmbito social, da combinação de atividades de preparação e investimento em formação sem, contudo, negligenciar a atuação das instituições sobre os fatores subjacentes relacionados, direta e indiretamente, com as ESP, incluindo os desastres.

Não podemos desconsiderar o contexto político atual em que se encontra nosso país, pois o cenário ambiental está diretamente relacionado com os rumos que as políticas públicas (ou a falta de) tomarão futuramente. Nos últimos anos, pudemos acompanhar uma série de políticas de proteção ambiental e garantia de direitos sociais ante os temas que envolvem saúde e o meio ambiente, incluindo a implementação do RSI no Brasil (2007), a criação da Política Nacional sobre Mudança do Clima (2009), ou ainda a Política Nacional de Proteção e Defesa Civil (2012). Mesmo com problemas para implementação nas esferas locais, essas políticas públicas representam avanços essenciais para nosso país.

Por fim, ao ser um problema mais grave e intenso para as comunidades vulneráveis (economicamente, socialmente ou politicamente), a relação entre sociedade civil e Estado - vínculo indispensável na gestão de risco - mostra-se em profunda tensão. As tensões aumentam à medida que a autonomia e a produção de informações e conhecimentos de instituições relacionadas com os temas aqui abordados são ameaçadas, ao mesmo tempo que imensos cortes para o financiamento de pesquisas são realizados, comprometendo um aspecto central das políticas globais e nacionais das últimas décadas: a produção de conhecimentos independentes e com autonomia. Associado a isso, no atual contexto global e nacional, são aprofundados os mecanismos de produção de condições de vulnerabilidades, sobrepondo riscos, ampliando os mecanismos perpetuadores das desigualdades no País e tornando opaco todo esforço instrumental e legislativo conquistados nos últimos anos. 


\section{Agradecimentos}

Agradecemos ao Doutor Prof. Carlos Machado de Freitas, pelas preciosas contribuições ao artigo.

\section{Colaboradores}

Silva MA (0000-0002-6021-4794)*, Xavier DR (0000-0001-5259-7732)*, Rocha V (00000003-2942-0837)* contribuíram igualmente para a elaboração do manuscrito.

\section{Referências}

1. Solomon C, LaRocque R. Climate Change - A Health Emergency. New Engl. J. Med. 2019; 380(3):209211.

2. Lucchini R, Hashim D, Acquilla S, et al. A comparative assessment of major international disasters: the need for exposure assessment, systematic emergency preparedness, and lifetime health care. BMC Public Health. 2017; 17(46):1-12.

3. Freitas C, Barcellos C, Asmus C, et al. Da Samarco em Mariana à Vale em Brumadinho: desastres em barragens de mineração e Saúde Coletiva. Cad. Saúde Pública. 2019; 35(5):e00052519.

4. Spiegel P, Le P, Ververs M, et al. Occurrence and overlap of natural disasters, complex emergencies and epidemics during the past decade (1995-2004). Conflict and Health. 2007; 1(2):1-9.

5. Sanders D, Sengupta A, Scott V. Ebola epidemic exposes the pathology of the global economic and political system. Inter J. Health Serv. 2015; 45(4):643656.
6. Steudler P, Melillo J, Feigl B, et al. Consequence of forest-to-pasture conversion on CH4fluxes in the Brazilian Amazon Basin. J. Geophy. Research: Atmospheres. 1996; 101(D13):18547-18554.

7. World Health Organization. Mudança climática e saúde humana - riscos e respostas: resumo atualizado. Tradução de Bié. Brasília, DF: Organização Pan-Americana da Saúde; 2008.

8. Freitas C, Silva D, Sena A, et al. Desastres naturais e saúde: uma análise da situação do Brasil. Ciênc. Saúde Colet. 2014; 19(9):3645-3656.

9. Bonatti TF, Carmo RL. Desastres tecnológicos: revisitando a discussão sobre a questão dos eventos de contaminação a partir da relação entre população, espaço e ambiente [internet]. In: Anais do $20^{\circ} \mathrm{En}-$ contro Nacional de Estudos Populacionais; 2016 Out 17-22; Campinas. Campinas: Unicamp; 2016. p. 1-21. [acesso em 2019 jul 20]. Disponível em: www.abep. org.br/publicacoes/index.php/anais/index.

10. Freitas C, Silva M. Acidentes de trabalho que se tornam desastres: os casos dos rompimentos em bar- 
ragens de mineração no Brasil. Rev. Bra. Med. Trab. 2009; 17(1):21-29.

11. Yamashita J, Shigemura J. The Great East Japan Earthquake, Tsunami, and Fukushima Daiichi Nuclear Power Plant Accident. Psych. Clinics North Am. 2013; 36(3):351-370.

12. Anyamba A, Chretien J, Britch S, et al. Global Disease Outbreaks Associated with the 2015-2016 El Niño Event. Scient. Repor. 2019; 9(130):1-14.

13. United Nations Children's Fund. Surto global de sarampo, uma ameaça crescente para crianças [internet]. 2019 [acesso em 2019 set 28]. Disponível em: https://www.unicef.org/brazil/comunicados-de-imprensa/surto-global-de-sarampo-uma-ameaca-crescente-para-criancas.

14. World Health Organization Brasil, Pan American Health Organization. Folha informativa - Febre amarela [internet]. 2019 [acesso em 2019 set 28]. Disponível em: https://www.paho.org/bra/index. php?option $=$ com_content\&view $=$ article $\&$ id $=5578: \mathrm{f}$ olha-informativa-febre-amarela\&Itemid $=875$.

15. World Health Organization. Declara vírus zika e microcefalia 'emergência pública internacional' [internet]. 2019. [acesso em 2019 set 28]. Disponível em: https://nacoesunidas.org/oms-declara-virus-zika-e-microcefalia-emergencia-publica-internacional/.

16. Organização Pan-Americana da Saúde. La salud en las Américas. Edición 2002. [internet]. 2019 [acesso em 2019 set 28]. Disponível em: http://iris.paho.org/ xmlui/handle/123456789/2747.

17. United Nations. Resolution adopted by the General Assembly on 25 September 2015 - Transforming our world: the 2030 Agenda for Sustainable Development. Washington, DC: United Nations; 2015.

18. Carmo E, Penna G, Oliveira W. Emergências de saúde pública: conceito, caracterização, preparação e resposta. Estud. Avançados. 2008; 22(64):19-32.

19. Brasil. Portaria GM/MS nº 2.952, de 14 de Dezembro de 2011. Regulamenta, no âmbito do Sistema Único de Saúde (SUS), o Decreto ${ }^{\circ}$ 7.616, de 17 de novembro de 2011, que dispõe sobre a declaração de Emergência em Saúde Pública de Importância Nacional (ESPIN) e institui a Força Nacional do Sistema Único de Saúde (FN-SUS). Brasília, DF. Diário Oficial da União. 14 Dez 2011. Disponível em: http://www.jusbrasil.com.br/diarios/DOU/2011/12/14.

20. Ventura D. Do Ebola ao Zika: as emergências internacionais e a securitização da saúde global. Cad. Saúde Pública. 2016; 32(4):e00033316.

21. United Nations Office for Disaster Risk Reduction. Sendai Framework for Disaster Risk Reduction: 20152030. Geneva: UNISDR; 2015.

22. United Nations Office for Disaster Risk Reduction. United Nations International Strategy for Disaster Reduction. Bangkok principles for the implementation of the health aspects of the Sendai framework for disaster risk reduction 2015-203. Geneve: UNISDR; 2016.

23. United Nations Framework Convention on Climate Change. Adoption of the Paris Agreement. Report No. FCCC/CP/2015/L.9/Rev.1 [internet] 2015. [acesso em 2019 jul 29]. Disponível em: http://unfccc.int/ resource/docs/2015/cop21/eng/109r01.pdf.

24. United Nations Office for Disaster Risk Reduction. Disaster risk reduction and resilience in the 2030 agenda for sustainable development. Geneva: UNISDE; 2015.

25. Aitsi-Selmi A, Murray V. Protecting the Health and Well-being of Populations from Disasters: Health and Health Care in the Sendai Framework for Disaster Risk Reduction 2015-2030. Prehosp. Disaster Med. 2015; 31(1):74-78.

26. Universidade Federal de Santa Catarina, Centro Universitário de Estudos e Pesquisas sobre Desastres. Atlas brasileiro de desastres naturais 1991 a 2010: volume Brasil. Florianópolis: CEPED; UFSC; 2012.

27. Loschi M. Desastres naturais: 59,4\% dos municípios 
não têm plano de gestão de riscos [internet]. 2012. [acesso em 2019 set 28]. Disponível em: https://agenciadenoticias.ibge.gov.br/agencia-noticias/2012-agencia-de-noticias/noticias/21633-desastres-naturais-59-4-dos-municipios-nao-tem-plano-de-gestao-de-ris cos?fbclid=IwAR12vz9h51BP7RPj2BOvSLQjHOFas MA7oJlKypoefwbW450h2bAkeNAEkOA.

28. Brasil. Ministério da Saúde, Secretaria de Vigilância em Saúde. Situação do Sarampo no Brasil - 2018-2019. [internet]. [acesso em 2019 set 28]. Disponível em: https://portalarquivos2.saude.gov.br/images/pdf/2019/ marco/19/Informe-Sarampo-n37-19mar19aed.pdf.

29. World Health Organization. Revisão do Regulamento Sanitário Internacional. 58 a Assembleia Mundial de Saúde, Item 13.1 da Agenda Genebra: OMS; 2005.

30. Brasil. Lei no 8.080 , de 19 de setembro de 1990. Dispõe sobre as condições para a promoção, proteção e recuperação da saúde, a organização e o funcionamento dos serviços correspondentes e dá outras providências. [internet]. Brasília, DF. Diário Oficial da União. 19 Set 1990. [acesso em 2019 jul 27]. Disponível em: http://www.planalto.gov.br/ccivil_03/ leis/18080.htm.

31. Teixeira M, Costa M, Viana I, et al. Vigilância em saúde: é necessária uma legislação de emergência? Rev. Direito Sanit. 2009; 10(2):126.

32. Teixeira M, Costa M, Carmo E, et al. Vigilância em Saúde no SUS - construção, efeitos e perspectivas. Ciênc. Saúde Colet. 2018; 23(6):1811-1818.

33. Freitas C, Rocha V, Silva E, et al. Conquistas, limites e obstáculos à redução de riscos ambientais à saúde nos 30 anos do Sistema Único de Saúde. Ciênc. Saúde Colet. 2018; 23(6):981-1996.

34. Conselho Nacional de Saúde. Resolução 588, de 12 de julho de 2018 [internet]. [acesso em 2019 jul 27]. Disponível em: https://conselho.saude.gov.br/resolucoes/2018/Reso588.pdf.
35. Brasil. Ministério do Meio Ambiente. Plano Nacional de Adaptação à Mudança do Clima - Volume II: Estratégias Setoriais e Temáticas. Brasília, DF: MMA; 2016.

36. Narváez L, Lavell A, Pérez Ortega G. La Gestión del Riesgo de Desastres. La Paz: Cebem; 2009.

37. Minervino A, Duarte E. Danos materiais causados à Saúde Pública e à sociedade decorrentes de inundações e enxurradas no Brasil, 2010-2014: dados originados dos sistemas de informação global e nacional. Ciênc. Saúde Colet. 21(3):685-694.

38. Silva IVM. Vulnerabilidade institucional do setor saúde a desastres no município de Nova Friburgo [dissertação]. Rio de Janeiro: Escola Nacional de Saúde Pública Sergio Arouca, Fundação Oswaldo Cruz; 2019. 158 p.

39. Birkmann J, Von Teichman K. Integrating disaster risk reduction and climate change adaptation: key challenges-scales, knowledge, and norms. Sust. Scienc. 2010; 5(2):171-184.

40. Schneider MC, Tirado MC, Rereddy S, et al. Natural disasters and communicable diseases in the Americas: contribution of veterinary public health. Vet Ital. 2012; 48(2):193-218.

41. United Nations Office for Disaster Risk Reduction. Prevention web. Disease detection in a box - a high-tech solution for emergency settings [internet]. 2019. [acesso em 2019 set 29]. Disponível em: https://www.preventionweb.net/news/view/64866?\&a=email\&utm source=pw_email.

42. Dunlop A, Logue K, Isakov A. The Engagement of Academic Institutions in Community Disaster Response: A Comparative Analysis. Pub. Health Repor. 2014; 129(6supl4):87-95.

\footnotetext{
Recebido em 29/09/2019

Aprovado em 04/02/2020

Conflito de interesses: inexistente

Suporte financeiro: não houve
} 